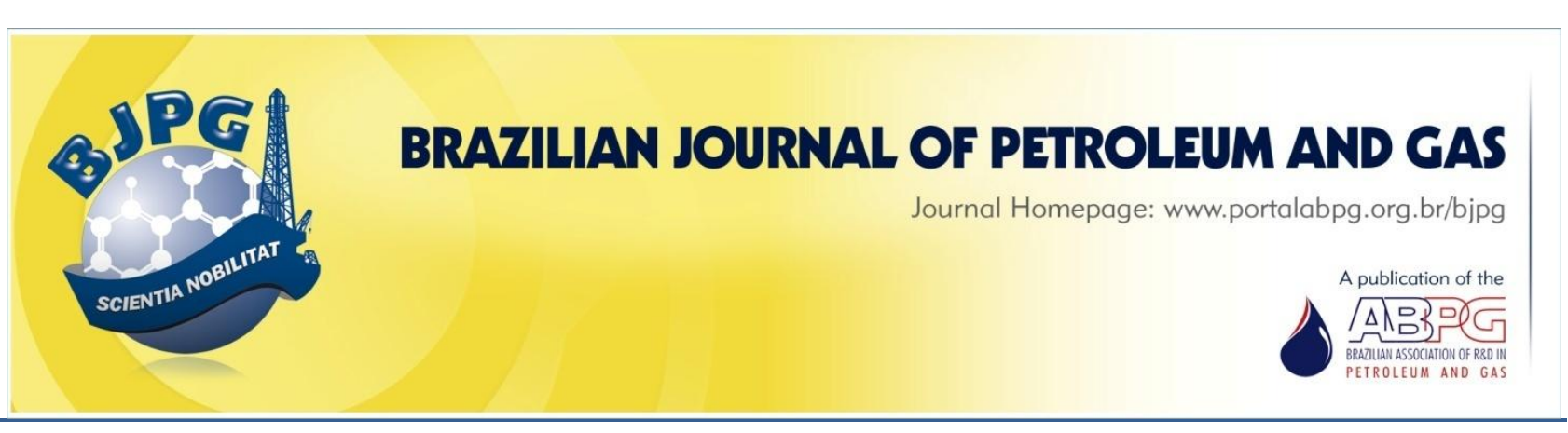

\title{
THE REVIEW OF FLOW ASSURANCE SOLUTIONS WITH RESPECT TO WAX AND ASPHALTENE
}

\author{
${ }^{\text {a }}$ Bimuratkyzy, K. ${ }^{1}$; ${ }^{\text {a Sagindykov, B. }}$ \\ ${ }^{a}$ Kazakh National Research Technical University named after K.I.Satpayev, Almaty, Kazakhstan \\ Received: 11.02.2016 / Revised: 07.06.2016 / Accepted: 09.06.2016 / Published on line: 12.07.2016
}

\begin{abstract}
This study examines mechanisms of wax and asphaltene precipitation and deposition, effects of the depositions on oil reservoir characteristics and performance, deposition prediction methods, deposition mitigation and removal techniques. Estimation results of several thermodynamic models of wax appearance temperature and subsequent deposition agree with each other. These estimations along with the limited field data comparisons suggest moderate success in modelling wax deposition, mainly because wax deposits depend on temperature. Asphaltenes' nature is unclear. Its mechanisms of precipitation, flocculation, and deposition remain unclear. So, the reliability of any forecast and simulation models can be questionable. Although there is a lack of documented evidence of any reliable method for predicting asphaltene deposition with high confidence, probably due to unrepresentative crude oil samples, there is reasonably good chemicals performance. These chemicals show that, if the deposition prevention is impossible, at least it can be controlled and managed. The lessons learned from different development projects and the best practices were used to define the flow assurance mitigation strategies. Since this study contains the necessary information on wax and asphaltene deposition, it can be used as a reference for further exploration of this field.
\end{abstract}

\section{KEYWORDS}

wax deposition; asphaltene deposition; deposition mechanisms

\footnotetext{
${ }^{1}$ To whom all correspondence should be addressed.

Address: Kazakh National Research Technical University named after K.I.Satpayev, Satpayev Str., Bld.22, Almaty, Kazakhstan. ZIP Code: 050013 | Telephone: +7 775 338-75-99 |e-mail: $\underline{\text { b kuralay@mail.ru }}$ doi:10.5419/bjpg2016-0010
} 


\section{INTRODUCTION}

A field project development usually is considered in phases. This is also true for flow assurance risk management, since it is in close relation with development phases. The better the flow assurance risks are defined during the project phases, the fewer problems the operations will encounter after the system is put on production (Song, 2008). This paper focuses on wax and asphaltenes issues for both onshore and offshore projects.

The layout of this paper is as follows: The nature of wax and asphaltene and the problems they cause are given first. Then, the characteristics and predictive methods of wax and asphaltene deposition will be described. Lastly, mitigation and removal techniques will be investigated (see Tables 1 and 2).

Paraffin is interchangeably referred to as waxes throughout the work.

\section{ASSESSING FLOW ASSURANCE RISKS DUE TO WAX AND ASPHALTENE DEPOSITION}

The potential of wax and asphaltenes deposition as well as the associated risks can be fully mapped from the crude oil analysis. Therefore, the quality of the fluid samples is very important. This is the moment to determine when and how much deposition will take place. That is why it is crucial to have representative preproduction samples to avoid wrong conclusions.

Some properties, which can indicate particular problems, have been emphasized. Wax related indication properties are cloud point and wax appearance temperature (WAT). The experimental techniques used to measure the WAT are standard ASTM D2500-88 or IP 219/82; cross polarized microscopy (CPM); quartz crystal microbalance (QCM) (Burgass \& Tohidi, 2011); differential scanning microscopy (DSM); light transmittance (LT); viscometry; filter plugging (FP); Fourier Transform (FT-IR) spectroscopy (Hammami et al., 2003); wax disappearance temperature (WDT). WDT can be determined by polarization microscopy; differential scanning calorimetry (DSC)
(Salameh, 2005), and rotational viscometer (Li \& Gong, 2010); pour point is a useful parameter for determining gel formation potentiality (Ellison et al., 2000). Pour point temperature can be identified by ASTM D-97 pour point test. Yield stress is used in determining the strength of a crude oil. The value could indicate potential restartability issues due to formed gel, measured with a rheometer (Ellison et al., 2000) or a cone and plate viscometer (Shepherd et al., 2013); wax porosity. Wax porosity affects wax deposition rate (Rosvold, 2008).

Generally, wax deposition potentiality can be identified by experimental systems such as cold finger, co-axial shearing cells, and pipe loops (Ellison et al., 2000).

In terms of asphaltenes, indicative parameters are hydrocarbon family distribution (saturates, aromatics, resins, and asphaltenes), asphaltene content, asphaltene onset pressure (AOP), and asphaltene deposition envelope (ADE).

Asphaltene content does not relate to the asphaltene instability, which causes precipitation. However, asphaltene stability depends on the asphaltene properties itself and the properties of the rest of the fractions of crude oil (Buriro \& Talib, 2012). Since asphaltene is an alkane, an insoluble component in crude oil, most of the testing measures its solubility (Alapati \& Joshi, 2013). The solubility of asphaltenes, resins, and maltenes within the crude is controlled by the ratio of polar to non-polar components and the ratio of high to low molecular weight components. Crude oils with higher resin and maltene content are more stable (Zekri et al., 2001). If the asphaltene content is unstable, then further action is needed to control and minimize asphaltene precipitation. If the asphaltene is stable, no further action is required (Buriro \& Talib, 2012). Therefore, evaluation of asphaltene stability is needed.

Similarly to wax testing, two types of fluids are used for asphaltene precipitation testing: pressurized live oil that closely represents the single-phase reservoir fluid at reservoir conditions and dead oil resulting from depressurization of the reservoir fluids, tested at ambient temperature (Alapati \& Joshi, 2013). 


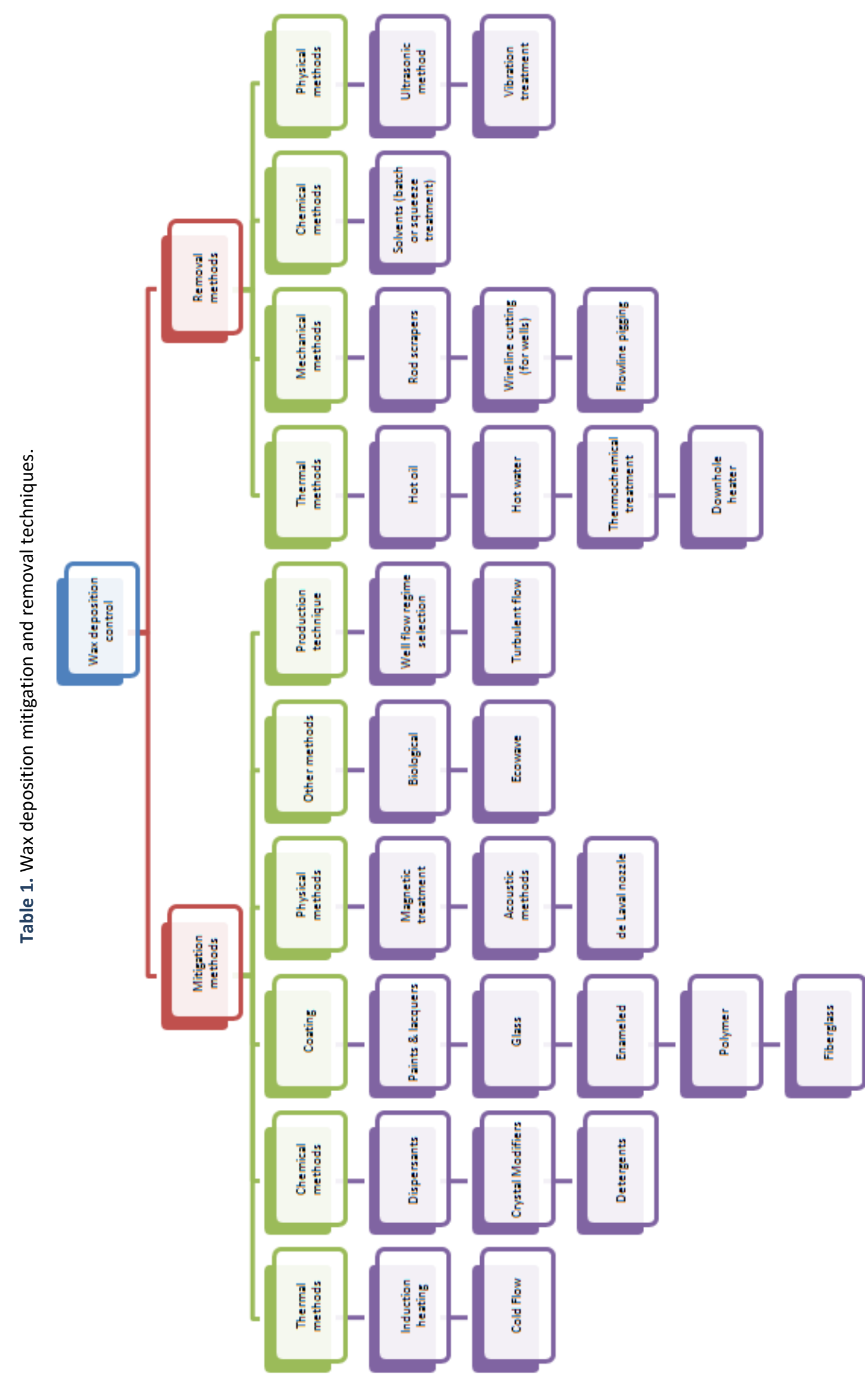


Table 2. Asphaltene deposition mitigation and removal techniques.

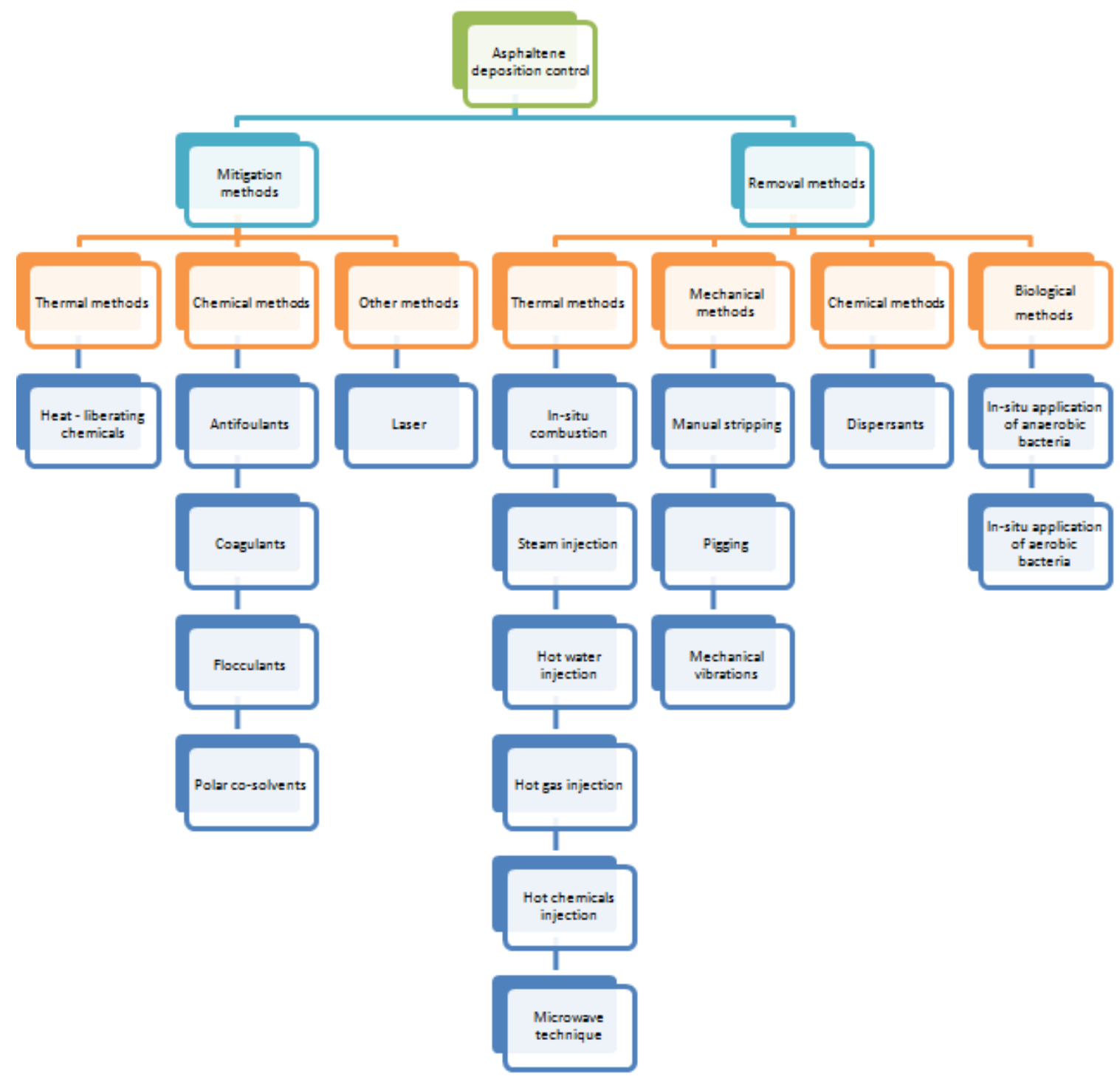

The SARA analysis (saturates, aromatics, resins, and asphaltenes) is useful in identifying oils with potential for asphaltene problems. Main approaches to separate crude oil into SARA fractions (Khanifar et al., 2011) are ASTM D2007, high pressure liquid chromatography, thin-layer chromatography (TLC), latroscan (combination of TLC with the flame ionization detection FID); and Colloidal instability index (CII), which is the ratio of saturates and asphaltenes over aromatic and resins. "Andrew Yen et al. (2001) reported that if CII $>0.9$, instability is indicated; if $\mathrm{CII}<0.7$, the crudes are generally stable. In between lies a range of uncertainty" (Misra et al., 2011). The De Boer's diagram also is used to determine asphaltenes stability in terms of saturation pressure and in-situ oil density (Misra et al., 2011). Refractive index (RI) can also be used to judge asphaltene stability. RI is identified as degree to which light refracts when passing through the medium. The RI decreases with a decrease in maltenes fraction, which can reduce asphaltene stability. However, thermal disaggregation can happen due to high temperature, even if the RI is decreased (Buriro \& Talib, 2012). Hydrogen to carbon (H/C) ratio influences asphaltene stability. If $\mathrm{H} / \mathrm{C}$ ratio decreases, the asphaltene becomes unstable (Buriro \& Talib, 2012). Normally, H/C ratio of asphaltenes is 1 - 1.3 (Alapati \& Joshi, 2013). Oliensis Spot, Heptane precipitation, and Flock Point Analysis titration tests also are used to evaluate asphaltene stability (Baker Petrolite manual, 2011).

PVTi (Pressure-Volume-Temperature) cell with solids detection system (SDS) is used to measure 
AOP. It can simulate field operation conditions in the laboratory and predict asphaltene precipitation tendency by the addition of $n$-heptane (Buriro \& Talib, 2012). Cardoso et al. (2003) mentioned two methods to determine the asphaltene onset. The first is the spectrophotometer method, in which the absorbance of the $n$-heptane/crude mixture is measured. The second is the optical method, in which the onset is determined through visual observations using optical microscope. Akbarzadeh et al. (2011), in their work, described the usage of a high-pressure deposition cell to generate and measure wax and asphaltene deposits from live fluids under realistic field conditions. However, obtained deposition rates cannot be applied directly to the field environment, its role is to link laboratory data to field.

The ADE is a useful tool for evaluating the potential and severity of asphaltene problems. Because the thermodynamic path can be seen from $A D E$, and if it is followed during reservoir oil recovery process, taking into account technical and economic considerations, asphaltene problems can be prevented or minimized (Leontaritis et al., 1994). Laboratory techniques to identify asphaltene precipitation envelope are: 1) gravimetric, 2) acoustic resonance, 3) near-infrared light scattering, and 4) filtration (Misra et al., 2011).

\section{DEPOSITION MECHANISMS}

Having high wax or asphaltene content in the crude does not necessarily mean they will be deposited. In fact, reservoir fluids with relatively small amounts of asphaltenes are more likely to cause problems during production than heavy oil with larger amounts of asphaltene, because of factors like variations in temperature, pressure, composition, $\mathrm{pH}$, flow regime among others (Khanifar et al., 2011).

\subsection{Wax deposition}

The Paraffin Deposition Process includes three stages: wax separation, wax crystals growth, and deposition of wax (Khanifar et al., 2011). This process can be explained by three mechanisms: molecular diffusion, shear rate, and Brownian diffusion (Bern et al., 1980; Misra et al., 1995). Molecular diffusion of wax molecules starts when the pipewall temperature reaches WAT and wax is precipitated, resulting in a concentration gradient between the dissolved wax in the turbulent core and the wax remaining in solution at the pipewall. Because of that dissolved wax diffuses towards the pipewall where it is subsequently precipitated. Deposition occurs if there is a temperature differential between bulk of oil and cold source. The temperature gradient increases with cooling until it reaches a steady value. As temperature difference decreases, temperature of the bulk oil in the pipeline becomes closer to ambient temperature, and the wax deposit rate gradually decreases. The wax deposition disappears when there is no temperature difference between the oil and the wall, even if the oil temperature is far below WAT (Rosvold, 2008).

Shear dispersion concerns already formed particles precipitated on the cold pipe surface due to wall roughness and intermolecular forces (Rosvold, 2008). Hsu and Brubaker (1995) proposed a semi-empirical technique to scale up laboratory wax deposition results for waxy crude production lines taking into account molecular diffusion and shear effects. Their data showed that under laminar flow conditions shear effect is almost negligible. However, under turbulent flow conditions, shear effect becomes significant and affects wax deposition rate. According to the experiments carried out at the University of Tulsa, no wax deposition was observed when the radial temperature gradient is zero; therefore the shear dispersion mechanism is unimportant in case of absence of temperature gradient (Rosvold, 2008).

Brownian movements of the small solid waxy crystals suspended in oil result in net transport, which is similar to diffusion, if these particles have a concentration gradient. "If referring to experiments by Burger et al. (1981), Brownian diffusion can be ignored"' (Rosvold, 2008).

Over time, wax deposit 'ages' and the wax content of the deposit increases, which results in a harder deposit: lower carbon number waxes are replaced with higher carbon number waxes as they become available from the oil passing the deposit an exchange takes place. As the average carbon number increases, the solubility decreases and the melting point and hardness increases (Baker Petrolite manual, 2011).

Wax deposition itself is a thermodynamically 
reversible process, i.e., if the temperature increases, the wax will resolve again in crude oil (Khanifar et al., 2011).

\subsection{Asphaltene deposition}

The mechanisms of asphaltene precipitation and deposition are very complex and are yet to be well understood. It has been widely accepted that asphaltene precipitation depends on thermodynamic conditions of pressure, temperature, and fluid composition.

During production, pressure changes from reservoir pressure to surface pressure and crude will experience some compositional changes: the light ends will expand relatively more than the heavier components of the crude, and it will continue up to the fluids bubble point pressure. Below the bubble point the light ends will leave the fluid as gas, resulting in a decrease in the volume of the light ends and causing a decrease in n-alkanes concentrations. Therefore, all crude oils will experience a minimum solvency just above the bubble point. Whether or not it will result in asphaltene precipitation will depend on the ratio of resins to asphaltenes, the crude solvency, and the temperature (Zekri et al., 2001). It is assumed that the asphaltene's micelle is kept in solution by a layer of resins. The strong tendency of resin to associate with asphaltene reduces the aggregation of asphaltenes (Leontaritis et al., 1994; Zekri et al., 2001). Since asphaltene and resin form the most polar fractions of crude oil (Zekri et al., 2001), any actions of chemical, electrical, or mechanical nature which result in alteration of the ratio of polar to non-polar components will consequently depeptize the asphaltene's micelle, leading to flocculation and precipitation of asphaltenes from the crude oil (Newberry \& Barker, 1985). Therefore, the addition of low surface tension organic fluids, i.e. below 24 dynes/cm at $25{ }^{\circ} \mathrm{C}$, such as gasoline, pentane, hexane, petroleum naphta, condensates, and diesel will precipitate asphaltenes. Blending with paraffinic crude oils will upset the ratio of solvent (aromatics) and solute (asphaltenes) and will also cause sludging of the asphaltenes from the crude oil, particularly if the asphlatenes fraction exceeds the maltenes fraction contained in the oil (Newberry \& Barker, 1985). Nevertheless, the addition of aromatics into low aromatic content crude oil will increase the crude stability for asphaltene thereby reducing the likelihood of asphlatene precipitation (Zekri et al., 2001).

Temperature effects are important because at higher temperatures resins solubility in the nalkanes increases greatly and asphaltenes become less soluble in the crude.

Asphaltene precipitation is a necessary condition for the formation of obstructions, but it is not a sufficient condition for deposition. According to Leontaritis et al. (1994), asphaltenes are deposited only after flocculation. During flocculation, the asphaltene micelles rearrange, by losing or gaining resin molecules, and form large entities. Some asphaltenes may drop out due to their large size. As these particles stick to a surface, they can create a flow assurance problem (Akbarzadeh et al., 2011).

Asphaltene deposition, on the other hand, is a much more complex process and also depends on flow's shear rate, surface type and characteristics, particle size, and particle-surface interactions (Akbarzadeh et al., 2011). Generally, two types of asphaltene deposits are possible: 1) hard coal like solid deposits and 2) sludges and rigid film emulsions (Newberry \& Barker, 1985).

Accepting that two types of asphaltene are present in crude oils: partly dissolved and partly in the form of colloidally dispersed particles, the depositional process can be reversible or irreversible depending on the type of deposited asphaltene (Zekri et al., 2001). However, the time required for asphaltenes to go back into solution may be considerably longer than the time required for the original precipitate to form (Khanifar et al., 2011).

Leontaritis et al. (1994) highlights that it is asphaltene flocculation, not deposition, which can be either reversible or irreversible. And the composition of the heterocyclic fraction of the oil determines asphaltene flocculation reversibility or irreversibility.

\section{DEFINING FLOW ASSURANCE MITIGATION STRATEGIES}

Mitigation strategy depends on sub-surface parameters like reservoir pressure, temperature, 
production profiles, number of wells, and production system configuration. These parameters determine how comprehensive flow assurance mitigation can be (Song, 2008). These parameters can respond question such as "is a flowline required to deliver chemicals (e.g. wax and/or asphaltene inhibitors)?" or "how often sampling should be collected?".

Extensive dynamic multiphase flow modelling (using dynamic multiphase flow simulators, e.g., PipeSim, WellFlo, and OLGA) will be performed to study system behaviour under normal and abnormal operation conditions. These conditions will also be applied to the thermo hydraulic parameters obtained from the multiphase modelling to improve wax and asphaltene mitigation strategies. Operations philosophy for planned shutdown and unplanned shutdown conditions will also be defined from the multiphase modelling (Song, 2008).

Compositional reservoir simulation technology (e.g. Eclipse 300), in its turn, along with advanced phase behaviour and fluid characterization, is capable of simulating/predicting the dynamic aspects of asphaltene precipitation/ flocculation/deposition throughout the life of reservoirs. It is possible to predict reduction of porosity and permeability, as well as alteration of wettability (Fazelipour, 2011). The advantage of simulation is prediction of asphaltene generation without the need for data generation from expensive downhole samples (Fazelipour, 2011). However, since asphaltene precipitation and deposition lacks properly understanding, its modelling remains dubious (Khanifar et al., 2011).

The advantage of the softwares is their costeffectiveness. However, wrong modelling leads to overassesment or underassessment of flow assurance risks, which can result in the overall system being either over- or under-designed (Song, 2008).

\section{BENCHMARKING AND OPTIMIZING SYSTEM PERFORMANCE}

Upon the availability of actual performance data of the production system, it is compared with the designed data to identify any performance gaps in case of new development projects (Song, 2008). If wax deposits are formed in already developing fields, following deposit tests can be used to measure the deposition: cold finger, cold-filter plugging, dynamic test loops, rolled-ball (flask test), and sonic testing (Becker, 1997) whereas studies on asphaltene deposition are conducted mainly either in microfluidic capillary flow experiments or in Taylor - Couette cells (Selfried et al., 2013).

Field techniques used to identify wax volume are caliper survey for production tubing. In case of a pipeline, solid deposits can be detected by means of pressure pulse technology which uses pressure profile in a pipeline. Pressure pulse can be used in combination with traces injection, for instance, Tracerco offers the TRACERCO DiagnosticsTM technique. Basically, the technique uses radioactive solid, liquid or gas, which follows the liquid in the pipeline. Then, sensitive radiation detectors are placed on the outside surface of the pipeline, and detect the tracer when it flows in the pipe (Rosvold, 2008). The disadvantage of this technique is that there is a high degree of uncertainty associated with the results and that carrying out a measurement is a complex and expensive procedure (Hoffmann et al., 2011). Hoffmann et al. (2011) proposed a new technology, heat pulse wax monitoring, for continuous monitoring of wax deposition in subsea pipelines. They carried out an experimental campaign in a lab rig using a heating element and a temperature sensor, to find a correlation between measured thermal response and the wax thickness by applying a short external heat pulse to the oil pipe. They claimed that if such a system could be installed in a subsea pipeline, it would allow for continuous monitoring of the wax build - up, identifying pigging frequency.

\section{FINALIZING THE SYSTEM OPERATIONS PROCEDURES}

At this stage the production system components will be changed from the original design due to various reasons. The corresponding flow assurance mitigations and operations procedures will need to be modified to reflect the changes (Song, 2008). For example, well regimes can be changed to particular rates at which wax does not deposit due to temperature increase higher than WAT (Anokhin \& Gafarov, 2008). Low 
flow rates affect wax deposition due to longer residence time of the oil in the tubing. Increased residence time leads to a lower oil temperature because of more heat loss and this, in turn, leads to wax precipitation and deposition (Misra et al., 1995).

Mitigation and removal techniques and methods for both wax and asphaltene are given in Tables 1 and 2, which were based on Anokhin and Gafarov's (2008) classification and superadded by information from Khanifar et al. (2011) and Newberry and Barker (1985). Mitigation and removal methods for each, wax and asphaltene, will be considered together. It should highlighted that correct selection of prevention treatment will avoid extremely expensive and insufficient 'trialand-error' procedures and even severe formation damages can be kept off (Garcia et al., 2003).

\section{WAX DEPOSITION TREATMENTS}

\subsection{Thermal treatment}

- Hot oiling and hot water. Using this technique, either oil or water is heated to 65-1650C (1503000F) (Newberry \& Barker, 1985) and pumped down the well tubing or casing to melt waxes that restrict downhole equipment. Crude oil for the operation should be checked for solids and cloud point. If the WAT is above the bottom hole temperature or the volume of solids exceeds $1 \%$, formation damage is likely to happen (Newberry \& Barker, 1985), then, hot oil should be replaced by hot water. Hot watering may use chemicals. By using water, some hot oil problems listed below can be avoided as water contains no paraffin, but other problems still exist. For instance, chemical added to the water can disperse the wax but water itself will not dilute or dissolve paraffin (Barker et al., 2003).

Becker (1997), in his work, mentioned the advantage of combining hot water surfactant treatment over hot oil: water's higher specific heat in comparison with oil, which allows water to arrive at the deposition site at a higher temperature. However, Barker et al. (2003) claims that wax cannot be melted out of the tubing below $150 \mathrm{~m}$ (500 feet), and, if the cloud point is high enough, wax deposition can start far below $150 \mathrm{~m}$. At this point, the hot oil/water treatment would remove only part of the deposition. Despite of that, it is a quite popular treatment among operation companies.

Some of the disadvantages of hot oiling (Barker et al., 2003) are: 1) it may cause pump and flowline plugging; 2 ) it may carry wax into the formation and cause permeability reduction; 3 ) it may deposit paraffin in the casing; 4) it causes safety concerns; 5 ) it requires significant heating (Becker \& Brown, 2009); 6) it can cause well damage by removing the lighter waxes and leaving the heavier waxes behind (Becker \& Brown, 2009).

- Thermal insulation of subsea flowlines and risers of the production wells. The insulation keeps the steady state flow temperature $30 \mathrm{C}$ above WAT over the field's lifetime (Cardoso et al., 2003). Nevertheless, it reports show that wax deposition can occur above the dead oil WAT in some systems. Therefore, it was suggested to keep the system's temperature greater than $90 \mathrm{C}$ above the dead oil cloud point (Ellison et al., 2000) because the same pressure WDT is always higher than WAT's, and the average temperature difference is about $9.40 \mathrm{C}$ (Li \& Gong, 2010). Pipeline insulation can include external insulation coating (Rosvold, 2008) or pipe-in-pipe flow lines and risers for ultradeepwater system (Cardoso et al., 2003). Plugs may be melted if an electrical pipe heater is installed.

- Downhole heaters. A continuous source of heat is used to melt paraffin or asphaltene deposits in the wellbore or on the tubing for a certain period, after which the melted material can be pumped up to the surface with oil production. The disadvantages of this method are high maintenance cost of the heating system, availability of electric power (Zekri et al., 2001).

- Cold Flow. The idea of cold flow is based on Coberly work (1942). He showed that the presence of foreign particles reduced wax deposition tendency, because they acted as nucleation sites. Wax crystals precipitated on them and were transported in the bulk, thus, the amount of solids adsorbed to the wall's surface was limited. Merino-Garcia et al. (2008) claimed that the feasibility of cold flow is validated if temperature gradient between hot oil and cold wall is eliminated (Al-Yaari, 2011). 


\subsection{Chemical treatment}

- Solvents. Generally, solvents are used to remove existing deposits. "They dissolve a specific weight of paraffin based upon the molecular weight of the wax, temperature, and pressure before the solvent power is exhausted" (Newberry \& Barker, 1985). Paraffin solvents are used in locations where it is impossible to use water and surfactant combinations. Because some crude oils are too sensitive to surfactants and always form emulsions or produced waters with very high concentrations of total dissolved solids, it limits greatly the range of paraffin compounds available. Solvents are best applied to wells that have very little standing oil in the casing above the pump. This promotes a concentrated product at the problem source rather than a very dilute solution of oil and solvent if a large volume of oil is present in the casing annulus (Newberry \& Barker, 1985).

"Carbon tetrachloride and Carbon disulfide have been pronounced as the universal solvents. Solvents such as kerosene, condensate and diesel oil are used to dissolve the low asphlatene content paraffin deposits" (Al-Yaari, 2011). Solvents selection method is wax solvation test (Baker Petrolite manual, 2011).

- Dispersants. Dispersants do not dissolve paraffin deposits but break them up into larger needle crystals which promotes better precipitation pack, with less interaction, and can be reabsorbed by the oil stream (Baker Petrolite manual, 2011). Therefore, squeeze jobs dispersant effectiveness partially depend on formation permeability (Al-Yaari, 2011). Dispersants may diffuse several times its own weight in paraffin but their application range is not wide as solvents. Typically, they are added into lower water cut systems and used in cold climates where paraffin inhibitors cannot be applied (Baker Petrolite manual, 2011).

Application: continuous into production system, batch treated into tanks (Baker Petrolite manual, 2011), squeeze jobs (Al-Yaari, 2011). Oil dispersant selection method is a tank bottom test.

- Detergents. "Detergents are class of surface active agents that work in the presence of water to water-wet paraffin particles, formation, tubing, and flowlines. These formulas break up deposits and prevent them from reagglomerating back together further downstream in the system" (Newberry \& Barker, 1985).

If well stimulation procedures such as acidizing or fracturing are planned, paraffin downhole deposition should be removed by paraffin dispersants and detergents prior to the stimulation. They can be carried by hot water, either fresh or produced water. However, $\mathrm{KCl}$ water can be used if clay swelling is a problem. Deposit removal will also prevent the paraffin deposition from being pushed deeper into formation during the treatment. Emulsion stabilization tendency caused by paraffin in returning acid can be destroyed by paraffin compounds added to acidizing solution. Prior to adding paraffin compounds to any treating fluids, these compounds should be checked for compatibility (Newberry \& Barker, 1985).

- Crystal Modifiers. These polymers interfere with the crystal growth and agglomeration processes and, therefore, inhibit the deposition of paraffin. In addition to paraffin inhibition they also have a tendency to change the rheological properties of the oil by reducing the pour point, viscosity, and yield value of the crude. For this reason, modifiers are added ahead of fracturing (Newberry \& Barker, 1985). Deliverability of the polymer under temperature restrictions is the major problem. The methods selected as Crystal Modifiers are pour point test, record viscosity vs. temperature, cold finger test, and yield stress value.

Paraffin inhibitors can reduce significant volumes of wax deposition. "The effectiveness of the paraffin treatment is dependent on crude oil composition, inhibitor chemistry, inhibitor dose rate, and the production conditions being treated" (Jennings \& Newberry, 2008). Both pressure and temperature can impact the stability of paraffin inhibitor formulations. For example, Jennings and Newberry (2008) emphasized that "products for deepwater subsea injection must remain fluid and solids-free at all conditions of temperatures and pressures the products experience in their respective injection paths - from storage tanks all the way through the umbilical and/or capillary 
injection lines." The latter's failure is a major concern in the industry.

The inhibition mechanism of the paraffin inhibitor is the prevention of wax incorporation into the deposit by weakening the deposit. Shear forces in the flow can remove weaken wax deposit (Jennings \& Newberry, 2008). It should be noted that paraffin inhibitors do not provide $100 \%$ inhibition. "Therefore, depending on inhibition levels, some additional method of remediating wax deposition may still be needed. These methods are usually pigging for flowlines and wireline cutting for wells. When used in conjunction with paraffin inhibitors, the frequency of pigging or wireline operations can be reduced. Also, the pigging and wireline cutting operations may potentially be performed easier since properly selected paraffin inhibitors produce weaker deposits. Hence, with paraffin inhibitor use, the danger of blocking a flowline with a stuck pig can potentially be decreased - both by reducing pigging frequencies and by making softer deposits")(Jennings \& Newberry, 2008).

To ensure that chemicals meet field/operator requirements, various qualification tests are performed to qualify a product. Above mentioned, the cold finger test also is used to screen for paraffin inhibitors. The $50 \%$ reduction correlates to good field performance because $90+\%$ inhibition in the field translates to $\sim 60 \%$ inhibition on conventional cold finger testing (Baker Petrolite manual, 2011). Thermal stability: for deepwater umbilical application system the first screening tests have a cold temperature stability of $205{ }^{\circ} \mathrm{C}$ (400F) and viscosity evaluation at ambient temperature (Jennings \& Newberry, 2008). For wells with high bottom hole, temperature chemicals are checked whether they can withstand this temperature. Viscosity evaluation: for deepwater umbilical application system viscosity evaluation is performed at ambient temperature (Jennings \& Newberry, 2008) along with the compatibility with other chemicals (i.e. corrosion inhibitors and demulsifiers). Dispersant test is used to screen for tank bottom and interface control chemicals. Flask test used to screen for surface active detergent/dispersant combinations for batch treatment or continuous applications for downhole or flowline control (Baker Petrolite manual, 2011).
To select chemicals for deepwater umbilical applications specialized tests such as capillary loop testing and high-pressure viscosity measurements can be performed.

Chemicals are applied most effectively if used as early in the production stream as possible. Bad logistics result in the improper addition of chemicals under less than optimal conditions, for instance, adding chemicals after the deposition 'spot' may prevent deposition downstream, but the source of the problem goes untreated (Garcia et al., 2003). So, chemical injection must be robust.

Advantages: chemicals may be the only method suitable for large offshore deepwater projects and is considered cost-effective (Barker et al., 2003). Chemicals have a potential for significant savings versus removal procedures (Garcia et al., 2003).

Disadvantages: all wells cannot be treated the same. Each well is individual. Successful application of inhibitors somewhere else does not mean it will work well everytime, trials have to be conducted on each well. Operating expenditures (OPEX) associated with chemical injection can be significant (e.g. in pumping wells the production of any gas make it impossible to get chemical to the bottom of a well without a flash system or capillary). Environmental regulations and downstream requirements can limit the types and volumes of chemicals, and no chemical solution may be available.

\subsection{Coating}

Jessen and Howell concluded that the wax amount deposited on a smooth surface is less than that deposited on steel (Misra et al., 1995). Different types of coating have been proposed to reduce wax deposition. However, their effectiveness is low: even if the rate of paraffin deposition is slower than on steel, the accumulation of the wax deposition will progress similarly to the rate of steel surfaces after inner wall is covered with a certain layer of wax, i.e. nucleation sites will be developed (AI-Yaari, 2011).

Disadvantages: cleaning problems, e.g. hot oiling or solvents use may damage poly-vinyl chloride (PVC) type pipes (Al-Yaari, 2011). 


\subsection{Mechanical treatment}

The following treatments are used to remove wax deposits from flow lines, producing tubing and pipelines: rod scrapers, wireline scrapers, flow line scrapers, free-floating piston scrapers (in gas lift wells (Al-Yaari, 2011)), pigging flow lines, and wirelining tubing (Zekri et al., 2001). To perform a mechanical clean-up by pig, topside and subsea facilities for running pigs in well flowlines and oil pipelines must be installed. Frequency of the cutting or wirelining (for well treatments) and pigging (to remove depositions in flowlines) depends on the wax deposition rate in an individual well. However, a maximum wax layer thickness of 2-3 $\mathrm{mm}$ is often used as pigging criterion (Labes-Carrier et al., 2002). "The improved flow due to the passing pig is probably caused by a combination of smoothing of the rough wax layer and removal of the wax back into the flowing well" (Bern et al., 1980). The pig selection depends on wax properties operating parameters.

Advantages: good cleaning is assured, minimal formation damage (Zekri et al., 2001).

Disadvantages: cutting tool stuck, expensive treatments (Oseghale \& Akpabio, 2012), e.g. if wireline is done more frequently, costs will go up (Barker et al., 2003) because special surface equipment and trained personnel will be required (Al-Yaari, 2011); pig stuck due to the deposit being too hard or the wax layer is too thick (Rosvold, 2008). Efficient utilization of pigging depends on proper wax deposition prediction (Al-Yaari, 2011). The scraping damages a well and decreases its productive life. Mechanical treatment may plug the perforations and increase the stability of oil-inwater emulsions.

\subsection{Combination of methods}

- Mechanical-chemical treatment. The most economic solution may be a combination of paraffin inhibitor (pumped at a lower than sufficient rate) and pigging (Baker Petrolite manual, 2011), especially for systems with high pigging frequencies. In contrast, if the pigging sufficiently removes wax deposition with little or no deferred production, then usage of paraffin inhibitors would be not necessary.

- Thermo-chemical treatment. This type of treatment can be applied to deposits that have changed their nature over a period of time and become more thermodynamically stable. For instance, SGNTM (Nitrogen generation system) treatment comprises of injecting the heat generating chemicals directly into the flow stream without interrupting it. Thanks to this technique significant production loss was prevented on some oil fields in Brazilian basin (Cardoso et al., 2003).

Disadvantages: some techniques require accurate information on the location of wax deposit and its wax fraction (AI-Yaari, 2011).

\subsection{Other treatments}

- EcowaveTM treatment (Baker Hughes). It is a chemical-free and environmentally friendly stimulation. This technology uses highfrequency radio waves and microwaves at low power to alter molecular bonds downhole, stimulating production increases by disrupting damaging deposits and improving reservoir wettability (Dean, 2010).

Equipment for a treatment consists of EcoWave unit, tuner, antenna system, and portable power source. After candidate well selection and approval from operator, the antenna is deployed in annulus or tubing at surface, and then attached to the Ecowave. System is powered and treatment begins for about $2-4$ hours.

The effectiveness of the technology was field-proved; with reported production increasing from 20 to more than 120 percent and treatment longevity to more than 60 days (Dean, 2010).

- Ultrasonic waves treatment. Towler et al. (2007) presented a novel way for mitigating wax deposition in a wellbore or pipeline. The treatment concept is to attach a device generating one ultrasonic frequency (used frequency was $120 \mathrm{kHz}$ ) to the production tubing and to produce one an ultrasonic frequency thereby breaking wax molecule bonds and preventing the wax from depositing on the production tubing walls. The results of such treatment are increased flow rates and production efficiency. Further work is required to determine the optimum frequencies. 
- Bacterial treatment. "It is been found that naturally occurring marine microorganisms, which have the ability to absorb paraffin, are able to remove effectively paraffin deposits or at least reduce the deposition over a certain time period" (Al-Yaari, 2011). Strata International has a bacterial product called PARAGONE which offers treatment programs that remove paraffin accumulations, inhibit corrosion or scale formation, and acts as emulsion breakers for production wells as well as for injection wells. The product is made of naturally occurring microorganisms suspended in a water-based solution that is pumped down the annulus. The mechanism of PARAGONE involves two processes: 1) degradation of the paraffin and 2) surfactant, produced by the bacteria cause the paraffin to become soluble in the oil again. The PARAGONE decreases oil viscosity, cloud point, pour point, and surface tension of oil to the rock grain, significantly improving oil recovery. The PARAGONE treatment procedure has been applied for more than 20 years in a number of oil fields with oils of different specifications. There has been no uncontrollable bacteria's cloning. The bacteria are fed with injected nutrients to control bacteria cloning on site. Once the nutrient injection stops, the bacteria disappear completely from the field.

Generally, in the oilfield, the microbial products are batch treated and pumped into the well-bore annulus. New batches are injected periodically to maintain the size of the microbial colony (AI-Yaari, 2011).

Advantages: Non-pathogenic, non-toxic, noncarcinogenic, non-flammable, non-combustible, environmentally safe (Al-Yaari, 2011).

Disadvantages: corrosion or souring, treatment is limited to wells producing water and it suffers from the difficulty to control the process (Zekri et al., 2001).

\section{ASPHALTENE DEPOSITION TREATMENTS}

\subsection{Chemical treatment}

The most popular method for asphaltene treatment is using chemicals. Their application areas are wide - chemicals can be used to treat the deposition in tubing, flowline, wellbore, formation, etc. Major types of chemical treatments are:

- Aromatic solvents. Solvents will dissolve bulk asphaltene deposits by breaking asphaltene to asphaltene bonds. Eventually, given enough time, all the aromatic based solutions will become fully saturated at about $30 \%$ asphaltene loading rate. Xylene alone will not remove asphaltenes that are attached to formation material such as clay; a dispersant is needed to remove adsorbed asphaltenes, which best are used to remove solid deposits (Newberry \& Barker, 1985);

- Asphaltene dispersants. They speed the breakup and dissolution of bulk asphaltene deposits over xylene alone, prevent sticking; best used to prevent the formation of sludge and rigid film emulsions (Newberry \& Barker, 1985);

- Asphaltene inhibitors. Buriro and Talib (2012) provided a good list of amphiphiles, polymers and surfactans that were evaluated for asphaltene inhibition effect. The following is the list of the ones which showed a good result in inhibition and are applied in many reservoirs: alkyl phenol; natural resin; non-ionic surfactant such as ethoxylategalcohols and phenols; vegetable oil (e.g. sweet almond, coconut essential oil); dodecyl benzene sulfonic acid (DBSA) (Buriro \& Talib, 2012). "Efficiency of asphaltene inhibitor can be tested in the laboratory using PVTi cell on the dead oil sample, however core flooding must done in order to check the compatibility of inhibitor with reservoir rock"' (Buriro \& Talib, 2012).

A number of additives can be used to clean up existing rigid film emulsion. The chemicals should be applied directly on the problem area and allowed to soak for 24 hours to minimize deferment, if the damage is severe longer soaking time is needed (Newberry \& Barker, 1985).

Chemical selection methods include: chemical screen with oliensis spot test, deposit salvation test, formation solids cleaning test, and acid sludge test.

The main disadvantage of chemical methods is environmental safety and personal exposure 
hazards concerns which may result in restrictions for many chemical-treatment materials (Zekri et al., 2001).

If well stimulation operations are planned, pretreatment of the well using solvent or hot water and surfactant the day prior to any well stimulation project should be considered as a deposition mitigation strategy.

\subsection{Thermal treatment}

This category of treating methods uses hot oiling and downhole heaters, which described in wax deposition thermal treatment. In addition to them, heat-liberating chemicals can be used: a mixture of equi-molar concentrations of ammonium chloride and sodium nitrate is pumped down with a buffer to delay the exothermic reaction until the fluid reaches the bottom-hole with a large quantity of nitrogen gas (Zekri et al., 2001).

Disadvantages: very expensive in comparison to conventional thermal methods, the process must be designed and closely monitored by a chemist on location (Zekri et al., 2001).

\subsection{0ther treatments}

- Bacterial treatment. See bacterial treatment of wax deposition.

- Combination of methods. Two or more methods mentioned above can be combined to find a solution, for instance, using hot chemicals which combine thermal and chemical methods (Zekri et al., 2001).

- Laser technology. Zekri et al. (2001) proposed a novel technique to clean asphaltenes with laser energy. In their experiments, they used bitumen/powdered limestone cores and brine. It was shown that laser energy alters the thermodynamics of the system, which results in a reversible process: some of the asphaltene redissolved back into the liquid phase. Laser treatment employed different laser intensities and different laser exposure times. Higher laser intensity provided better improvement of the rock - damaged permeability. The effect of exposure time indicated that there is an optimum exposure time beyond which no additional improvement on the damaged core permeability was observed. The most optimistic case yielded $49 \%$ permeability recovery factor at exposure time of 2 hours, whereas the modest result was $4 \%$ at 30 minutes exposure time.

Advantages: environmental friendly.

Disadvantages: scaled studies using modified device is required before this technique can be used in the field.

\section{CONCLUSIONS}

In conclusion, an exhaustive list of methods available for prediction of wax and asphaltene production issues, as well as shortlisted mitigation and removal techniques and their limitations are given. Wax and asphaltene flow assurance considerations needed to be in agreement with other flow performance constraints treatment.

The following suggestions are recommended for further work considerations:

- Usage of dead oil or live oil to identify WAT. In many cases stock tank sample gives very conservative predictions (Shepherd et al., 2013). Considering the effect of dead crude oil thermodynamics (pressure, temperature) may provide an insight on the interpretation of WAT measures using different techniques, and right value will be taken. However, some projects require live deposition testing or flow loop and this is selected on a case by case basis (Shepherd et al., 2013);

- Watercut influence on wax deposition. Water does not change the solubility of paraffins (Misra et al., 1995). However, water has the potential effect to decrease bulk oil cooling, and, consequently, to increase the well stream heat capacity (i.e. retain heat) and avoid contact of wax on the tubing wall (Anokhin \& Gafarov, 2008). Shepherd et al. (2013) modelled wax contact to the tubing wall which resulted in a significant difference between low and high water cuts. The exact influence of water was not determined in detail since this would require flow loop testing;

- Consider nanotechnology to reduce asphaltene deposition; 
- Development of surface coatings to prevent or minimize asphaltene deposition;

- Wax and asphaltene relationship.

\section{NOMENCLATURE}

AOP - Asphaltene Onset Pressure

ASTM - American Society of Testing Materials

bbl - barrel

CF - Cold Finger

CII - Colloidal Instability Index

CPM - Cross Polarized Microscopy

DSM - Differential Scanning Microscopy

EOR - Enhanced Oil Recovery

FID - Flame Ionization Detection

FP - Filter Plugging

FT-IR - Fourier Transform Infra-Red

LT - Light Transmittance

PVC - Poly-Vinyl Chloride

PVT-Pressure-Volume-Temperature

QCM - Quartz Crystal Microbalance

$\mathrm{RI}$ - Refractive Index

SDS - Solids Detection System

TLC-FID - Thin-layer chromatography with flame ionization detection

WAT - Wax Appearance Temperature

WDT - Wax Disappearance Temperature

\section{REFERENCES}

Akbarzadeh, K.; Eskin, D.; Ratulowski, J.; Taylor, S. D. Asphaltene deposition measurement and modelling for flow assurance of subsea tubings and pipelines. Paper OTC-22316-MS, Offshore Technology Conference, Rio de Janeiro, Brazil, 2011. http://dx.doi.org/10.4043/22316-MS

Alapati, R. R.; Joshi, N. New test method for field evaluation of asphaltene deposition. Paper OTC-24168-MS, Offshore Technology Conference, Houston, Texas, USA, 2013. http://dx.doi.org/10.4043/24168-MS
Al-Yaari, M. Paraffin wax deposition: mitigation and removal techniques. Paper SPE-155412-MS, SPE Saudi Arabia section Young Professionals Technical Symposium, Dhahran, Saudi Arabia, 2011. http://dx.doi.org/10.2118/155412-MS

Anokhin, A.; Gafarov, Sh. To choice the preventioned paraffin sedimentation rate of centrifugal electric pump equipped wells. Neftegazovoe Delo Journal, tom 6:2, 2008. (in Russian).

Baker Petrolite manual, Texas, USA, 2011.

Barker, K. M.; Waugh, K. L.; Newberry, M. E. Cost-effective treatment programs for paraffin control. Paper SPE 80903, SPE Production \& Operations Symposium, Oklahoma City, USA, 2003. http://dx.doi.org/10.2118/80903-ms

Becker, J.R. Crude oil waxes, emulsions, and asphaltenes. Penwell Corporation, Tulsa, Oklahoma, USA, 1997.

Becker, J. R.; Brown, J. M. Quantum effects imparted by radio frequencies as a stimulation method of oil production. Paper SPE 124144, SPE Annual Technical Conference and Exhibition, New Orleans, Louisiana, USA, 2009.

http://dx.doi.org/10.2118/124144-ms

Bern, P. A.; Withers, V. R.; Cairns, R. Wax deposition in crude oil pipelines. Paper EUR 206, European Offshore Petroleum Conference and Exhibition, London, England, 1980.

http://dx.doi.org/10.2118/206-1980-MS

Burgass, R.; Tohidi, B. Development of and validation of small volume multi-tasking flow assurance tool. Paper SPE 145946, SPE Asia Pacific Oil and Gas Conference and Exhibition, Jakarta, Indonesia, 2011.

http://dx.doi.org/10.2118/145946-ms

Buriro, M.; Talib, S. M. Asphaltene precipitation and prevention: A strategy to control asphaltene precipitation. Paper SPE 163129, SPE/PAPG Annual Technical Conference, Islamabad, Pakistan, 2012. http://dx.doi.org/10.2118/163129-MS

Cardoso, C.; Alves, I.; Geraldo, S. Management of flow assurance constraints. Paper OTC 15222, Offshore Technology Conference, Houston, Texas, USA, 2003. http://dx.doi.org/10.4043/15222-MS 
Choiri, M. Study of $\mathrm{CO}_{2}$ effect on asphaltene precipitation and compositional simulation of asphaltenic oil reservoir. Master thesis, University of Stavanger, Stavanger, Norway, 2010.

Dean, G.; Perkins, R. Chemical - free stimulation renews mature well production. DEW Journal, $p$. 21-25, 2010.

Ellison, B. T.; Gallagher, C. T., Frostman, L. M.; Lorimer, S. E. The physical chemistry of wax, hydrates, and asphaltene. Paper OTC 11963, Offshore Technology Conference, Houston, Texas, 2000. http://dx.doi.org/10.4043/11963-MS

Fazelipour, W. Predicting asphaltene precipitation in oilfields via the technology of compositional reservoir simulation. Paper SPE 141148, SPE International Symposium on Oilfield Chemistry,Woodlands, Texas, USA, 2011.

http://dx.doi.org/10.2118/141148-MS

Garcia, M.; Henriquez, M.; Orta J. Asphaltene deposition prediction and control in a Venezuelan north Monagas oil field. Paper SPE 80262, SPE International Symposium on Oilfield Chemistry, Houston, Texas, USA, 2003.

http://dx.doi.org/10.2118/80262-MS

Hammami, A.; Ratulowski, J.; Coutinho, J. A. P. Cloud points: can we measure or model them? Petroleum Science and Technology Journal, v. 21: 3-4, p.345-358, 2003.

Hoffmann, R.; Amundsen, L.; Schüller, R. Online monitoring of wax deposition in subsea pipelines, Measurement Science and Technology, p. 1-13, v.22, 2011.

http://dx.doi.org/10.1088/0957-0233/22/7/075701

Hsu, J. J. C.; Brubaker, J. P. Wax deposition scale -up modelling for waxy crude production lines. Paper OTC 7778, $27^{\text {th }}$ Annual OTC, Houston, Texas, USA, 1995.

Jennings, D. W.; Newberry, M. E. Application of paraffin inhibitor treatment programs in offshore developments. Paper OTC 19154, Offshore Technology Conference, Houston, Texas, USA, 2008. http://dx.doi.org/10.4043/19154-MS
Khanifar, A.; Alian, S. S.; Demiral, B.; Darman, N. B. Study of asphaltene precipitation and deposition phenomenon during WAG application. Paper SPE 143488, SPE Enhanced Oil Recovery Conference, Kuala Lumpur, Malaysia, 2011.

http://dx.doi.org/10.2118/143488-MS

Labes-Carrier, C.; Ronningsen, H. P.; Kolnes, J.; Leporcher E. Wax deposition in north sea gas condensate and oil systems: Comparison between operational experience and model prediction. Paper SPE 77573, SPE Annual Technical Conference and Exhibition, San Antonio, Texas, USA, 2002. http://dx.doi.org/10.2118/77573-MS

Leontaritis, K. J.; Amaefule, J. O.; Charles, R. E. A systematic approach for the prevention and treatment of formation damage caused by asphaltene deposition. Paper SPE 23810-PA, SPE Production \& Facilities, v.9 (3), p. 157-164, 1994. http://dx.doi.org/10.2118/23810-pa

Li, H.; Gong, J. The effect of pressure on wax disappearance temperature and wax appearance temperature of water cut crude oil. Proceedings of the twentieth International Offshore and Polar Engineering Conference, Beijing, China, 2010.

Misra, S.; Abdulla, D.; Bazuhair, M. K.; Aboukhsem, A. A.; Stenger, B. A.; Al-Katheeri, A. B. Management of asphaltenes deposition in a giant carbonate onshore oil field, Abu Dhabbi, UAE. Paper SPE-140278-MS, SPE Middle East Oil and Gas Show and Conference, Manama, Bahrain, 2011. http://dx.doi.org/10.2118/140278-MS

Misra, S.; Baruah, S.; Singh, K. Paraffin problems in crude oil production and transportation: A review. Paper SPE-28181-PA, SPE Production \& Facilities, v.10 (1), p. 50-54, 1995.

http://dx.doi.org/10.2118/28181-PA

Newberry, M. E.; Barker, K. M. Formation damage prevention through the control of paraffin and asphaltene deposition. Paper SPE 13796, SPE Production Operations Symposium, Oklahoma City, Oklahoma, 1985. http://dx.doi.org/10.2118/13796-MS

Oseghale, C. I.; Akpabio, E. J. Managing paraffin wax deposition in oil wells - related problems in Nigerian oil fields. Paper SPE-163037-MS, SPE Annual International Conference and Exhibition, Abuja, Nigeria, 2012.

http://dx.doi.org/10.2118/163037-MS 
Rosvold, K. Wax deposition models. Master thesis, Norwegian University of Science and Technology, Stavanger, 2008.

Salameh, M. Effect of wax appearance temperature and wax disappearance temperature on pipeline design. Master thesis, Heriot-Watt University, Edinburgh, 2005.

Selfried, C. M.; Al Lawati, S.; Crawshaw, J. P.; Boek, E. S. Asphaltene deposition in capillary flow. Paper SPE-166289-MS, SPE Annual Technical Conference and Exhibition, New Orleans, Louisiana, USA, 2013. http://dx.doi.org/10.2118/166289-MS

Shepherd, A. G.; Vandewyer, T.; Rafik, D.; van Kins,S.; Baksteen, E.; Cheong, A. Risks, mitigation and management of wax production chemistry in SAGD environment: downhole to surface and beyond. Paper SPE-165109-MS, SPE European Formation Damage Conference and Exhibition, Noordwijk, Netherlands, 2013.

http://dx.doi.org/10.2118/165109-MS
Song, S. Managing flow assurance and operation risks in subsea tie-back system. Paper OTC 19139, Offshore Technology Conference, Houston, Texas, USA, 2008. http://dx.doi.org/10.4043/19139-MS

Towler B. F.; Ashok Kumar Chejara; Saeid Mokhatab. Experimental investigations of ultrasonic waves effects on wax deposition during crude - oil production. Paper SPE-109505, SPE Annual Technical Conference and Exhibition held in Anaheim, California, USA, November 11-14, 2007. http://dx.doi.org/10.2118/109505-MS

Zekri, A. Y.; Shedid, A. S.; Alkashef, H. A novel technique for treating asphaltene deposition using laser technology. Paper SPE-70050-MS, SPE Permian Basin Oil and Gas Recovery Conference, Midland, Texas, 2001. http://dx.doi.org/10.2118/70050-MS 